\title{
GOVERNANÇA CORPORATIVA NA EMPRESA FAMILIAR: um estudo bibliométrico sobre a evolução do tema no período de 2011 a 2017
}

\section{CORPORATE GOVERNANCE IN THE FAMILY COMPANY: a bibliometric study on the evolution of the subject in the period from 2011 to 2017}

\author{
Lucas Kendy Tokimatu ${ }^{\mathrm{I}}$ \\ Rosemary Rocha Caligioni ${ }^{\text {II }}$ \\ Cristiane Arroyo III \\ Márcia Mitie Durante Maemura ${ }^{\mathrm{IV}}$ \\ Lesley Carina do Lago Attadia Galli V
}

\begin{abstract}
RESUMO
Este é um estudo bibliométrico sobre a evolução das pesquisas sobre o tema "Governança Corporativa na empresa familiar", no período de 2011 a abril de 2017. O objetivo geral é produzir indicadores bibliométricos que mostrem como os estudos científicos sobre como o referido tema tem evoluído no cenário mundial. Considerou-se como base amostral os artigos publicados sobre empresa familiar na base de dados Scopus. Logo depois, foi realizado um estudo teórico, de caráter exploratório e abordagem quantitativa, utilizando a bibliometria como método de pesquisa. Foram selecionados e analisados 210 artigos por meio de técnicas de análise de gráficos. Chegou-se à conclusão de que os estudos qualitativos sobre empresa familiar, no geral, possuem caráter mais teórico e prendem-se mais na análise documental carecendo de estudos que utilizem outras metodologias, enquanto isso, por outro lado, os estudos quantitativos passaram a utilizar mais a análise baseada na estatística multivariada do que a descritiva. Já a produção de estudos referente a governança corporativa, apesar de mostrar-se tímida, foram feitas de forma mais interconectadas com outros temas da empresa familiar. Recomenda-se maior valorização de estudos que empreguem metodologias mais diversas e maiores publicações de estudos sobre governança corporativa para o melhor entendimento da complexa realidade das empresas familiares.
\end{abstract}

Palavras-chave: Empresa familiar. Governança Corporativa. Estudo Bibliométrico.

\begin{abstract}
This is a bibliometric study about the evolution of research on the topic "Corporate Governance in the family business," from 2011 to april of 2017. The general objective is to

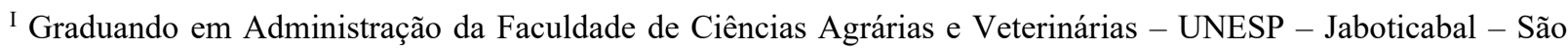
Paulo - SP - E-mail: lucastokimatu@gmail.com

II Mestranda em Administração pela Faculdade de Ciências Agrárias e Veterinárias - UNESP - Jaboticabal - São Paulo - SP - E-mail: r.caligioni@unesp.br

III Profa. Dra. Pesquisadora do Grupo CEPECAF- Centro de Pesquisa e Capacitação da Empresa Familiar FCAV-UNESP E-mail: csarroyo@terra.com.br

IV Profa. Dra. Da Universidade Federal de Uberlândia - UFU - Uberlândia - Minas Gerais - Brasil. E-mail: mitie.maemura@gmail.com

V Profa. Dra. da Faculdade de Ciências Agrárias e Veterinárias - UNESP - Jaboticabal - São Paulo. E-mail: lesley.attadia@unesp.br.
\end{abstract}




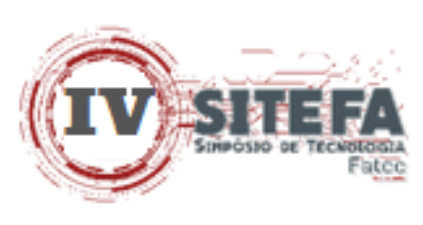

produce bibliometric indicators that show how scientific studies about said subject has evolved in the world scenario. It was considered as a database article published on the topic in the data bases Scopus. After this, a theoretical study, exploratory and quantitative approach was carried out, using bibliometric as a research method. They were selected and analyzed 210 articles using graphic analysis techniques. It was concluded that qualitative studies about family business, in general, have a more theoretical approach and are more focused on documentary analysis, lacking studies that use other methodologies, whereas, on the other hand, the quantitative studies started to use more analysis based on multivariate statistics than the descriptive one. The production of studies on corporate governance, despite been timid, were made more interconnected with the other subjects of the family business. It is recommended to increase the values os studies that use more diverse methologies and larger publications of studies on corporate governance to better understand the complex reality of family business.

Keywords: Family Business. Corporate Governance. Study Bibliometric.

Data de submissão do artigo: 30/06/2021.

Data de aprovação do artigo: 01/09/2021.

DOI: $10.33635 /$ sitefa.v4i1.183

\section{INTRODUÇÃO}

Litz (1995), Miller, Miller e Lester (2016), Paiva, Oliveira e Melo (2008) e Reyna e Encalada (2012) percebem a complexidade em se definir a expressão "empresa familiar", devido à existência de várias definições encontradas para esta, as quais tentam capturar a sua essência da forma mais completa e precisa possível.

Levou-se em consideração a percepção dos autores como principal dificuldade, bem como o reconhecimento da importância que as empresas familiares são para a economia (Bethlem, 1994), coloca-a como boa fornecedora de trabalho, acrescentado de PadillaMeléndez, Diéguez-Soto e Garrido-Moreno (2015), que a consideram como uma importante forma de negócios, bem como " forma predominante de organização empresarial ao redor do mundo", de acordo com Sharma, Chrisman e Gersick (2012) apud Padilla-Meléndez, Diéguez-Soto e Garrido-Moreno (2015, p. 1065) e para a sociedade (vista, para Paiva, Oliveira e Melo (2008), como geradora de empregos, força esta que fortalece o mercado consumidor e que melhora a distribuição de renda), este assunto começou a despertar interesse de vários estudiosos, passando a ser objeto de estudos científicos em tempos recentes e possibilitando o aumento de trabalhos e artigos publicados sobre o referido tema (CHRISMAN et al., 2008 apud VELASCO; PARRA; GARCÍA, 2011; PADILLAMELÉNDEZ; DIÉGUEZ-SOTO; GARRIDO-MORENO (2015).

A importância das empresas familiares é corroborada a partir da observação de que correspondem a 50\% no PIB brasileiro e a $85 \%$ da mão-de-obra empregada, de acordo com dados obtidos no FFI em 2016. Bethlem (1994) publicou em seu trabalho a importância que as empresas familiares representavam em quase $90 \%$ dos grandes grupos empresariais brasileiros.

Levando em consideração as várias definições encontradas para empresa familiar, Moreira, Altaf e Trocolli (2016) notaram que este tipo de organização é formado por duas dimensões: a organização e a família. Posteriormente, é considerado que se trata de empresas 


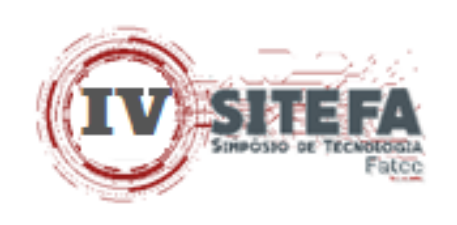

onde a família detém o controle e envolvem-se na tomada de decisão (OLIVEIRA; ALBURQUERQUE; PEREIRA, 2012; REYNA; ENCALADA, 2012). Neste último conceito, conclui e acrescenta Oliveira, Albuquerque e Pereira (2012) que uma empresa é dita familiar, quando a família participa em pelo menos um destes três elementos: controle acionário, envolvimento da gestão e transição multigeracional.

Apesar das várias descobertas e evolução de pesquisas, muitas áreas ligadas diretamente à empresa e família em conjunto, não são exploradas, havendo escassez de pesquisas científicas em várias temáticas. Padilla-Meléndez, Diéguez-Soto e Garrido-Moreno (2015), apontaram falta de estudos e de revisões de literatura ligando e estudando juntamente, inovação e empresa familiar. No caso do tema "Governança corporativa e empresa familiar, observou-se poucos estudos que de acordo com as buscas na base de dados Scopus, dos 210 artigos amostrados e retornados sobre empresa familiar, somente 21 têm como objetivo principal entender a relação empresa familiar e governança corporativa. Daí a importância por investigações tanto qualitativas, quanto quantitativas.

Levando em conta que o estudo da Governança Corporativa esta perspectiva é considerada ainda incipiente, este trabalho apresenta a seguinte questão de pesquisa: como se apresenta a evolução do estudo sobre os principais temas de empresa familiar e da governança corporativa nos anos de 2011 a 2017 no cenário mundial?

O objetivo geral é produzir indicadores bibliométricos que mostrem como os estudos científicos sobre o tema "Governança Corporativa na empresa familiar" têm evoluído no cenário mundial, tomando como base nas publicações mais recentes, de 2011 até 2017, disponibilizadas na base de dados Scopus.

A opção em realizar um estudo bibliométrico sobre empresa familiar e relacioná-la com governança corporativa, foi pelo motivo de se tratar de um tema recente, pouco explorado, estando, geralmente, envolto de impressões de autores (BETHLEM, 1994) e de ser alvo de senso comum, sendo comumente, desvalorizado e pouco estudado, fato comprovado pelo número reduzido de pesquisas científicas existentes que que buscam entender a associação empresa e família ou então, ou áreas relacionadas com o referido tema, apontado pelos estudos de Padilla-Meléndez, Diéguez-Soto e Garrido-Moreno (2015), que não há conexão entre inovação na empresa familiar.

\section{EMPRESA FAMILIAR}

Para Gallo e Sveen (1991, apud OLIVEIRA; ALBUQUERQUE; PEREIRA, 2012), uma empresa é caracterizada como familiar se a família possuir o maior capital da empresa, permitida a gestão deste ambiente de trabalho pelos familiares. Já Tagiuri e Davis $(1985$, apud Oliveira, Albuquerque e Pereira, 2010), definem-na como organização é onde a família possui influência na direção e administração dos negócios, através de seus laços de parentesco.

Apesar da dificuldade de se encontrar uma definição segura e precisa, existem duas dimensões em todas as empresas familiares: a empresa e a família. Embora haja união e dualidade entre esses dois elementos, os objetivos são bastante distintos e objetivos: enquanto a empresa preocupa-se mais com a competitividade do mercado (a racionalidade e a objetividade como suas principais características), a família procura a maior união entre os integrantes e uma relação social mais harmoniosa (subjetividade e afetividade intrínsecos a esta realidade) (OLIVEIRA; ALBURQUERQUE; PEREIRA, 2012).

A influência da família na tomada de decisão, faz com que estes tipos de empresa se diferenciem das empresas não-familiares (MALONI; HIATT; ASTRACHAN, 2017), e as 


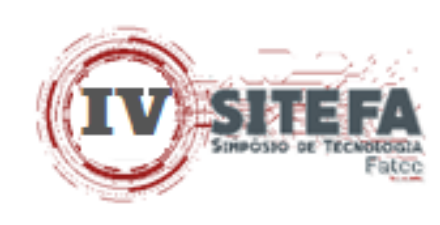

empresas familiares tendem a ser mais orientadas a estratégias de longo prazo. As empresas familiares buscam projetos de longo prazo que sejam lucrativos, uma vez que querem a organização se desenvolva e seja herdada por futuros membros da família (REYNA; ENCALADA, 2012), são mais conservativas, preocupam-se com a própria reputação, e tendem a evitar os riscos, ou seja, evitar investimentos muito arriscados (REYNA; ENCALADA, 2012; MALONI; HIATT; ASTRACHAN, 2017).

Importante enfatizar que as empresas familiares têm preferência por colocar relativos em altas posições, mesmo estes sendo menos eficientes do que gerentes profissionais disponíveis no mercado. Quando a família está no controle, geralmente aproveitam-se dos seus direitos e a posição ocupada dentro da organização, levando a uma posse e controle excessivos pelo dono, podendo ocasionar problemas de gerenciamento e administração. Assim, é visto o quanto as famílias envolvidas, para muitos estudiosos, tentam acrescentar suas próprias riquezas a fim de assegurar seus interesses pessoais (REYNA; ENCALADA, 2012).

Os interesses pessoais, de acordo com Maloni, Hiatt e Astrachan (2017) podem reter maior importância do que os próprios objetivos e metas financeiras da organização, fazendo com que os objetivos e a performance se diferenciem de outras empresas. Essa valorização pelas metas não-financeiras, estão associadas pelo desenvolvimento e valorização de seu capital social e de seu relacionamento externo, a fim de garantir o bem-estar e uma imagem positiva para a empresa. Porém, o desenvolvimento de um forte capital social ainda pode ser dificultado, na medida que as empresas familiares podem desconfiar de pessoas de fora da empresa (DYER JR; WHETTEN, 2006 apud MALONI; HIATT; ASTRACHAN, 2017).

Nota-se que as decisões das empresas familiares, tendem a preservar o $S E W$ Socioemotional Wealth (riqueza socioemocional) acima de todos os outros objetivos, sendo que sua perda implica em redução de seus status, não alcance das expectativas familiares e perda de intimidade (GÓMEZ-MEJÍA et al, 2007 apud MALONI; HIATT; ASTRACHAN, 2017). Os problemas financeiros geralmente são considerados quando tendem a afetar negativamente o SEW, já que esta representa como o elemento mais importante da essência da empresa familiar que a separa de outras organizações (BERRONE et al, 2012 apud MALONI; HIATT; ASTRACHAN, 2017).

\subsection{Sucessão}

De acordo com Lambrecht (2005 apud OLIVEIRA; ALBUQUERQUE; PEREIRA, 2010), sucessão é o processo em que ocorre a transferência de valores e cultura da empresa de uma pessoa para outra e de uma geração para outra, podendo tanto ser um profissional no mercado, quanto um membro da família. A temática sucessão é um dos tópicos mais analisados sobre empresa familiar, Reyna e Encalada (2016). Esse interesse se dá pelo fato que sucessão está ligada como a principal causa de mortalidade das empresas familiares, onde muitas destas deixam de existir depois da morte do fundador, fato este corroborado pelos dados da Secretaria de Economia (2012), que estima que 60\% das empresas não conseguem sobre sobreviver até a segunda geração e os $85 \%$ até a terceira.

É visível a mudança de mentalidade de uma geração para outra, sendo que umas tendem a ser mais conformistas e outras tendem, mais inovadoras e empreendedoras (REYNA; ENCALADA, 2016; MILLER; MILLER; LESTER, 2012). Estudos feitos por Reyna e Escalada (2015), com amostras de empresas familiares públicas no México, 


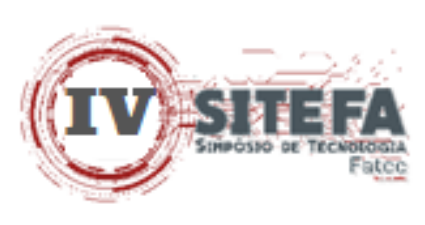

constatou que, pelo menos no aspecto financeiro, as famílias de primeira e segunda geração são mais aversas aos riscos e são mais conformistas (levando consequentemente, numa menor taxa de crescimento das organizações nesses períodos), mentalidade bastante divergente da terceira, que na pesquisa, mostrou-se mais disposta a enfrentar o risco, contribuindo para um feito positivo na performance financeira da empresa.

Já Miller, Miller e Lester (2012) apontaram, fora do âmbito financeiro, que a primeira geração que tende a ser mais empreendedora, pelo fato desta ser fundadoras da empresa, tendo espírito mais proativo (são fundadores por definição), enquanto as seguintes seriam mais conformistas. Os autores completam esse raciocínio apontando a divisão entre strategy literature, onde as empresas familiares tendem a adoção de estratégias inovadoras e nãoconformistas, investindo em métodos que permitam se desenvolver no mercado e garantir superioridade na performance e institutional literature, que diz que elas são mais conformistas, em parte porque procuram perseguir objetivos ligados ao $S E W$ e evitar serem alvos de desconfianças dos stakeholders.

Barrédy (2016) explica, os diferentes tipos de cenários com relação à transmissão de poder na sucessão: a) Family business priority, está relacionado a quando alguém escolhe seu herdeiro, podendo ser este qualquer membro familiar. Isto asseguraria, segundo ele, a impossibilidade de conflitos familiares; b) Family business co-construction, está associado à riqueza socioemocional $(S E W)$, mas a diferentes objetivos entre membros da família. Neste, é escolhido o herdeiro, baseado na confiança e lealdade, porém tendo objetivos e metas diferentes, podendo levar ao conflito; c) Multiple heir's transmission, baseia-se quando o predecessor não escolhe seu herdeiro ou então, deseja, por transferir para mais de uma pessoa. Isto porém, envolve o risco, segundo o autor, pois aumenta o número de membros da família no poder na empresa, aumentando, substancialmente, a chance de conflitos entre aqueles que estão no poder e d) Exit familiy, visto como o pior cenário dentre os demais, porque neste ambiente, os relacionamentos socioemocionais são frágeis (falta de livre tomada de decisão entre a família), e as metas são diferentes entre os membros da família, já que o predecessor não faz nenhuma escolha de seus herdeiros, podendo levar à família sair da empresa.

\subsection{Profissionalização}

A presença da figura do administrador profissional e na separação entre propriedade e gestão, estão ligadas a profissionalização da empresa familiar, garantindo a impessoalidade e racionalidade nas tomadas de decisão a fim de resolver problemas ligados à relação empresafamília. (OLIVEIRA; ALBUQUERQUE; PEREIRA, 2012). Os autores destacam a necessidade da inserção de alguém externo à organização familiar, que tenha experiência e seja capacitado para separar a família da gestão de seus negócios, gerando na separação entre daquele que irá ficar com a propriedade e daquele quem cuidará da gestão.

Porém Dekker et al. (2015) aponta que não é correto afirmar que os membros da família não são profissionais e que deveriam ser rapidamente substituídos para que a empresa cresça ou então, considerar a simples presença de um gerente não membro da família e considerar como empresa familiar com profissionalização.

Para Oliveira, Albuquerque e Pereira (2012), entenderam que a alternativa de capacitar a família, através da profissionalização de seus membros, a fim de prepará-los para administrar a empresa, deve ser considerado. Isto acabará influenciando na escolha de seus respectivos sucessores, visto que a sucessão está muito ligada à competência de seus herdeiros, que está associada à profissionalização de seus trabalhadores. 


\section{(i.j)}

\subsection{Governança corporativa na empresa familiar}

De acordo com a BM\&FBOVESPA (2014), governança corporativa é a reunião de medidas que incentivem e controlem a tomada de decisões em conformidade com as metas das organizações. Como meios de controles apresentam-se o conselho de administração ativo e independente, se formado por membros internos e externos, um sistema de sistema de remuneração de administradores que atenda aos interesses da organização e seus acionistas, controle para verificar se tudo está de acordo com a legalidade da empresa e práticas sistemática de resultados para aqueles envolvidos na organização. Essas medidas permitem um bom relacionamento entre todas as partes envolvidas, ou seja, o conselho, a empresa, os acionistas, dentre outros.

Para Brenes, Madrigl e Requena (2011), o conceito de governança corporativa tem em sua estrutura três elementos: 1) stockholders' assembly - formado por todos os stockholders da organização, tendo autoridade final sobre as decisões desta; 2) board of directors - onde reside um dos problemas de governança corporativa já que afeta futuramente no "bem-estar" da empresa como, por exemplo, os membros deste conselho são escolhidos, quais são suas responsabilidades e como funcionam e 3) top management team - time de gerência sendo fruto e consequência do board of directors. O grande desafio, de acordo com os autores, está no elemento board of directors, uma vez que cada empresa familiar é única e tem seus próprios valores e cultura, e nem todas elas possuem membros do conselho formados somente membros da família, pois procuram por empregados que assegurem a longevidade da empresa.

Conclui os autores que um conselho formado por membros e não-membros da família permitem o equilíbrio que ajudam no desenvolvimento da empresa, pois enquanto os primeiros possuem experiência e conhecimento de seus negócios, os segundos enriquecem através de suas visões mais objetivas e profissionais que ajudam a resolver os conflitos na dimensão empresa-família.

\section{METODOLOGIA DA PESQUISA}

O presente trabalho, com o propósito de realização de uma revisão de literatura tem abordagem sistemática e quantitativa através de Pesquisa Bibliográfica.

A bibliometria, ou pesquisa bibliométrica, trata-se, dentre os vários tipos de técnicas para quantificar e expor a difusão do conhecimento científico para fins de estudo, de um instrumento quantitativo que visa gerir e mapear produções científicas, segundo não têm o objetivo de impor verdade únicas e absolutas, mas sim de procurar explicar um determinado acontecimento para permitir o acesso ao conhecimento sobre quaisquer assuntos para serem submetidos a uma avaliação e possibilitar a identificação das principais tendências de cada área (CARDOSO, 2005, SANTOS; KOBASHI, 2009 apud SANTOS; SANTOS; MALDONADO, 2010).

O procedimento utilizado foi a seleção de palavras-chave que se relacionam com o tema da pesquisa, sendo os termos "corporate governance family business", "empresa familiar", "family business" e "governança corporativa empresa familiar".

Após a definição das palavras-chave, procedeu-se a pesquisa dos artigos na base de dados Scopus, no percurso temporal de 2011 a 2017, e considerou a análise de conteúdo dos artigos para a construção da pesquisa bibliográfica. 


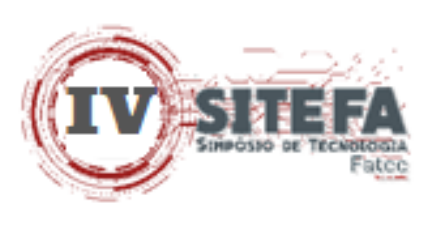

\section{RESULTADOS E DISCUSSÃO}

Os resultados foram obtidos a partir da observação dos 271 artigos analisados, sendo que 210 deles foram divididos com base em: natureza, abordagem, método de pesquisa, coleta de dados e procedimento de análise. Com a tabulação dos artigos, foi possível acompanhar a evolução dos trabalhos publicados no Scopus sobre empresa familiar de 2011 até abril de 2017.

Entretanto, percebeu-se certo interesse pelo estudo envolvendo questões sociais como diversificação e principalmente, questões de gênero (sexto tema mais abordado pelas pesquisas) envolvendo a importância da figura feminina na empresa familiar.

Foi possível observar todos os temas explorados ao longo desses anos. Pontua-se que crescimento e performance, junto com sucessão foram os temas mais explorados no período atual sobre empresa familiar. Governança corporativa por sua vez, ocupou a quinta posição, com 21 trabalhos publicados sobre empresa familiar, demonstrados no Gráfico 1.

Gráfico 1 - Índice de temas publicados sobre empresa familiar

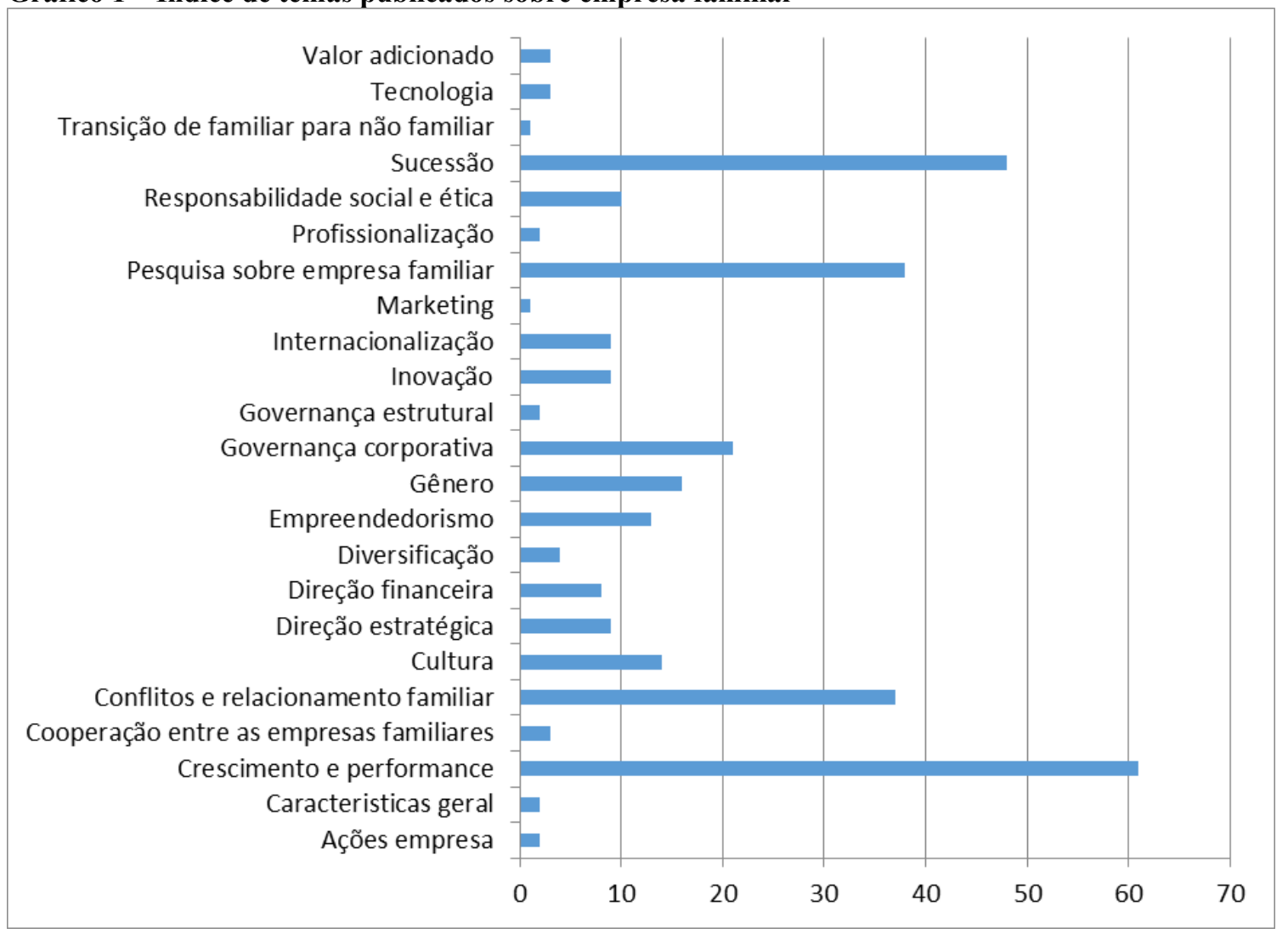

Fonte: Elaborado pelos autores (2017)

Chama-se a atenção de novos temas que estão começando a aparecer no escopo empresa familiar, a saber: cooperação entre empresas familiares. Seus 3 artigos publicados, vistos somente em 2015, porém mostram uma abordagem ainda muito superficial, curta e tímida sobre o novo assunto, indicando o quanto este ainda precisa ser mais bem estudado para sua melhor compreensão. 


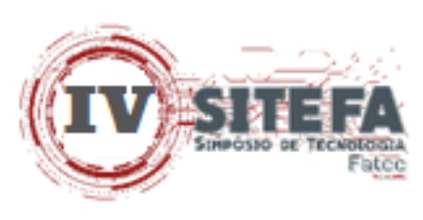

Outros temas poucos estudados, são marketing, o qual contabilizou apenas 1 artigo (escrito em espanhol) revelando que muitos pesquisadores não estão fazendo a associação entre empresa familiar e marketing, gerando em escassas informações sobre a influência desse departamento nas empresas geridas por famílias.

Quanto em relação a Governança corporativa, diz-se que esta vem sendo atualmente, trabalhada conjuntamente com outros temas, em especial crescimento e sucessão (temas de grande destaque na empresa familiar), revelando o quanto governança é um tema amplo que precisa ser estudado levando-se em conta outras questões associadas a empresa familiar. Todavia, ressalta-se ainda o pequeno número de publicações que trabalham com o referido tema, como por exemplo em 2016 e 2017 (este contado até abril), os quais apresentaram 1 e 0 trabalhos que o focassem.

O total de publicações de artigos sobre Governança Corporativa, como mostrado no Gráfico 2, foi bastante baixa (com 21 artigos registrados no Scopus) se comparada com outros temas como sucessão (apresentando 48 trabalhos ao longo do período) e crescimento (com 61 artigos disponíveis). $\mathrm{O}$ maior número registrado que trabalham com governança no ano foi 7 , em 2015.

Gráfico 2 - Número de artigos sobre governança corporativa

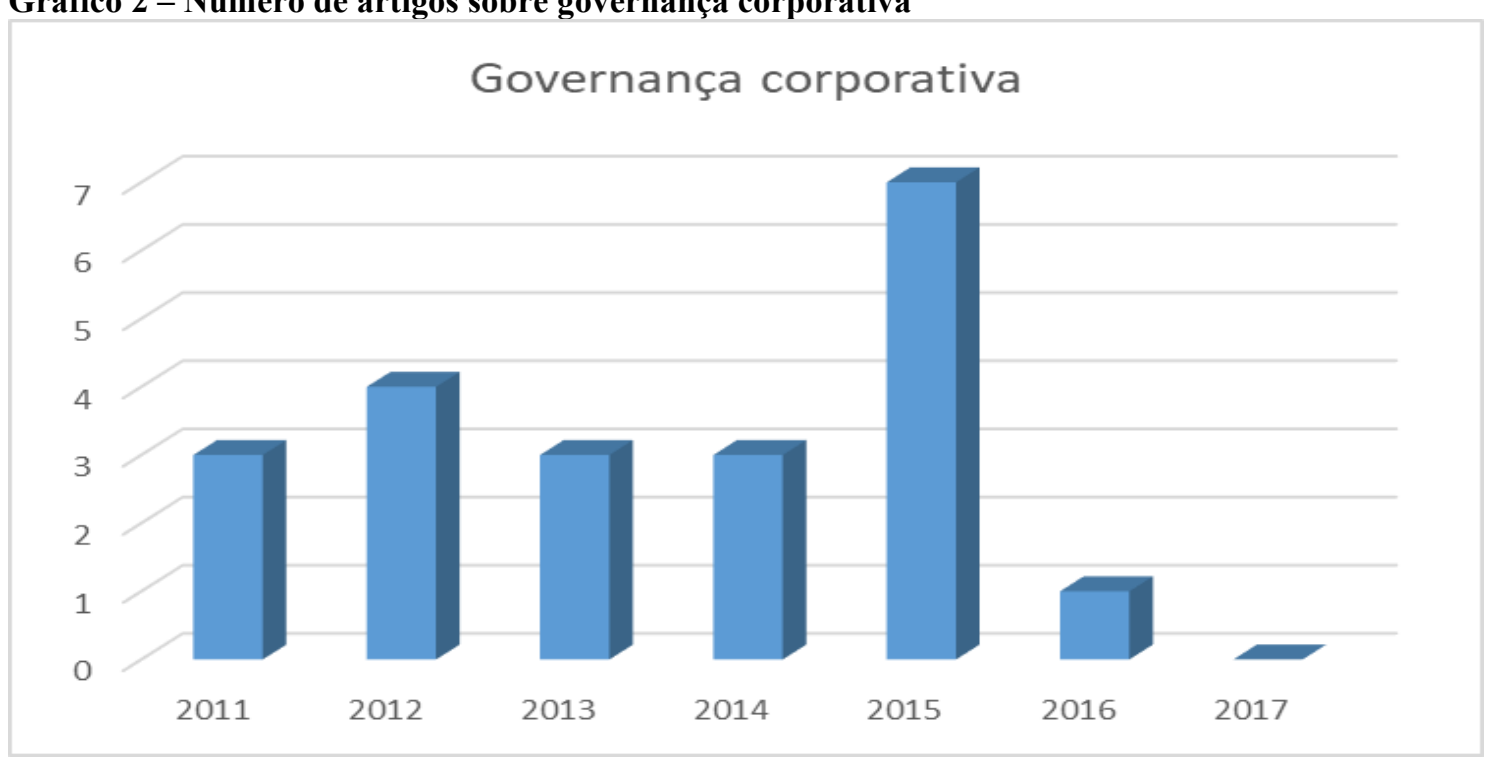

Fonte: Elaborado pelos autores (2017)

Em abordagem, por sua vez, visto no Gráfico 3, percebe-se grande número de artigos qualitativos no período analisado (sendo o maior número visto em 2015, com 24 publicações) e aumento de estudos quantitativos a partir de 2013 (sendo 2016 o período correspondente ao maior número de publicações), sendo contabilizados no total, 110 artigos qualitativos e 98 artigos quantitativos publicados de 2011 a abril de 2017. Ressalta-se ainda 2 trabalhos que utilizam as duas abordagens, um em 2014 e o outro em 2015. 


\section{(IV) SITEFA}

12 Sintosio of Trevolesia

Gráfico 3 - Número de artigos classificados com base na abordagem

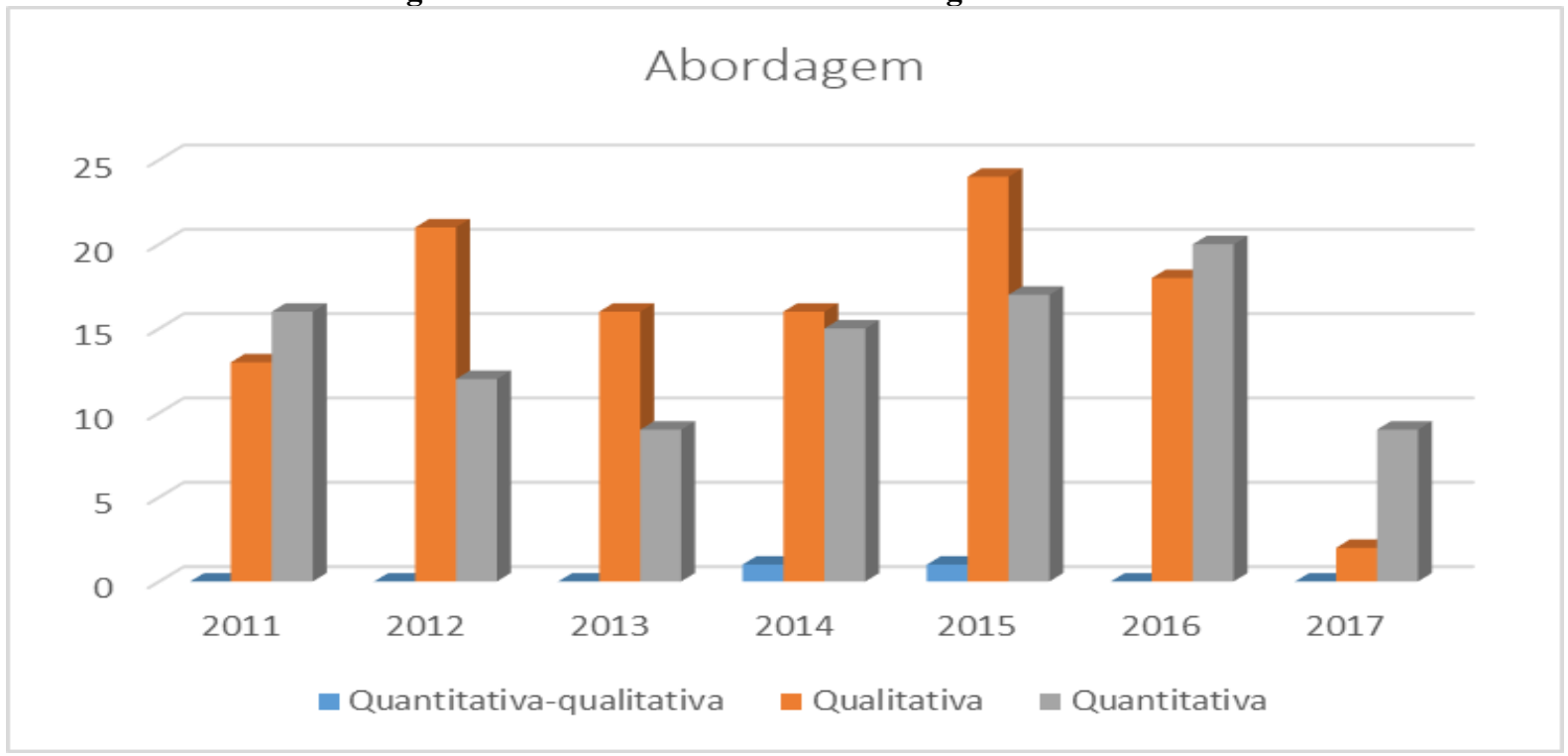

Fonte: Elaborado pelos autores (2017)

No Gráfico 4, verifica-se que os dados foram coletados, principalmente, por meio de uma análise documental e, também, por questionário fechado. Ademais, percebe-se a partir 2015, o aumento da utilização de dados analisados a partir de uma base secundária.

\section{Gráfico 4 - Número de artigos classificados em coleta de dados}

\section{Coleta de dados}

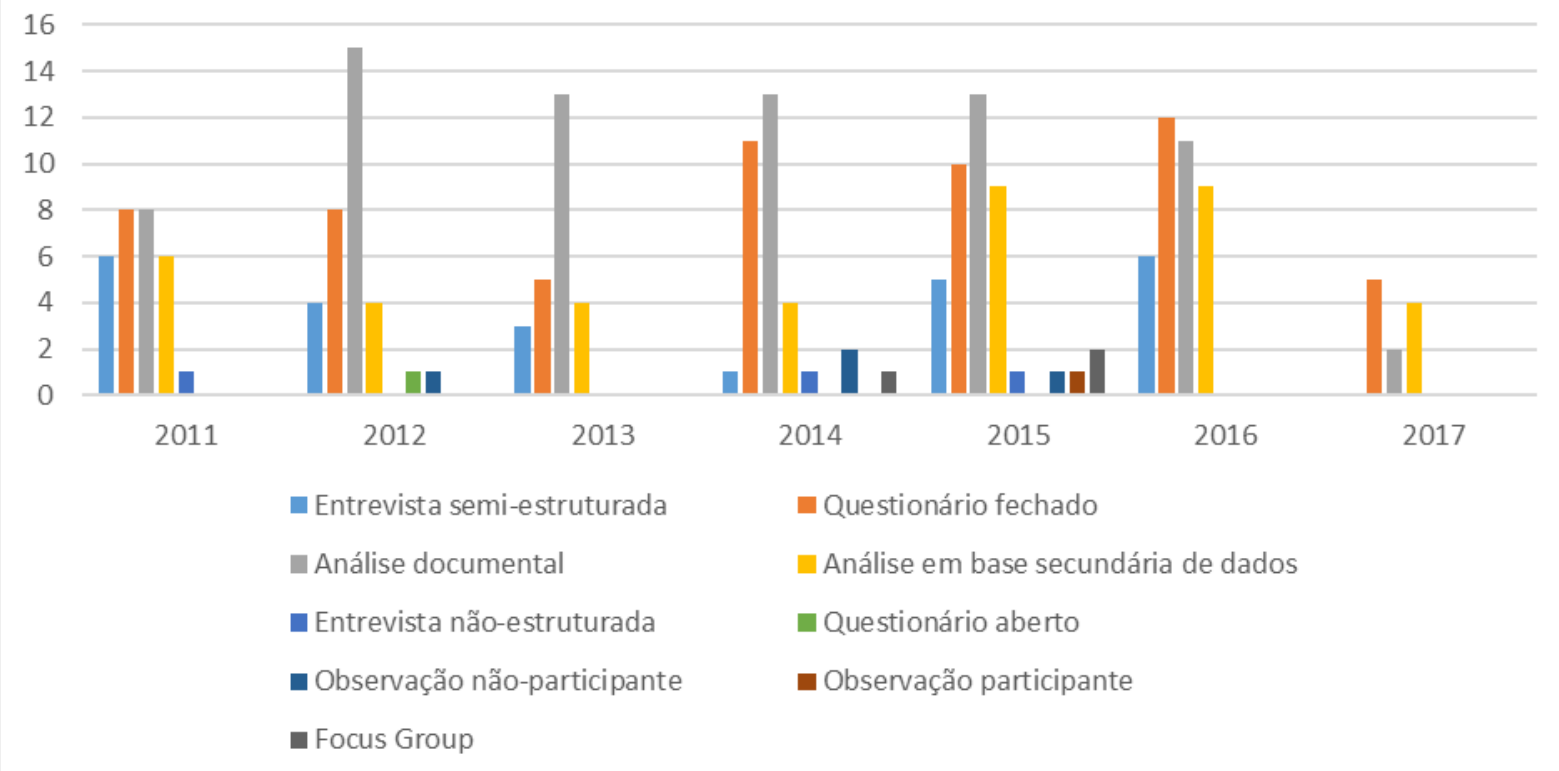

Fonte: Elaborado pelos autores (2017)

Já no Gráfico 5, percebe-se a predominância de artigos redigidos a partir de análise de conteúdo em praticamente todos os anos (sendo registrados no total 77 artigos durante o período analisado), com exceção dos anos de 2011 (superado pela estatística descritiva) e de 


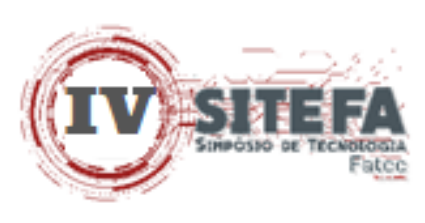

2017 (a maioria feita com base em estatística multivariada). É válido notar ainda o aumento do número de trabalhos feitos a partir da estatística multivariada, sendo que em 2012, passou a se notar número maior deste tipo de estatística, do que a descritiva. Um outro elemento a ser pontuado no gráfico é que se detectou apenas um artigo, este feito em 2012, que utilizou a análise de indução lógica.

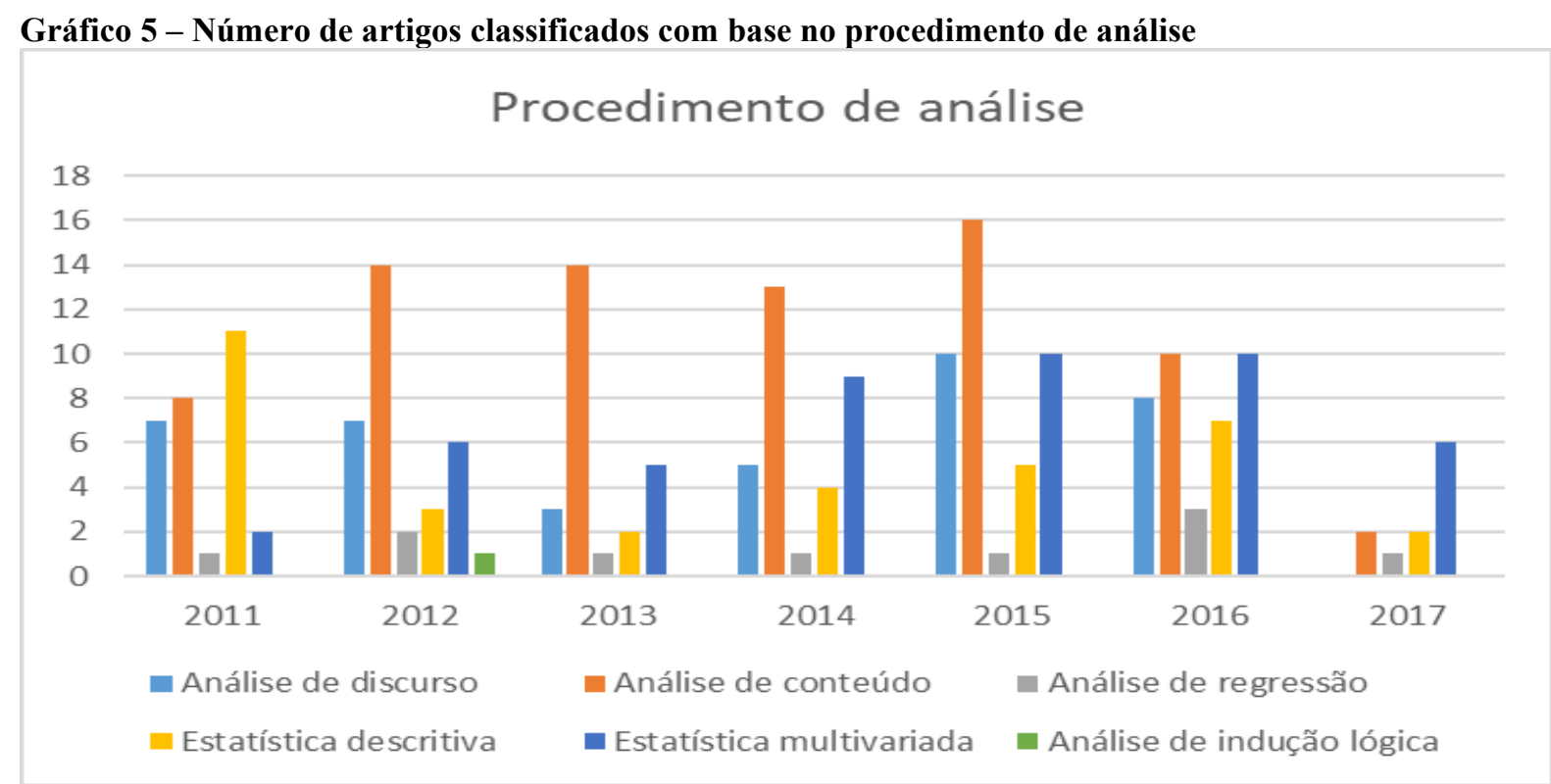

Fonte: Elaborado pelos autores (2017)

\section{CONSIDERAÇÕES FINAIS}

O presente trabalho objetivou acompanhar a evolução da publicação de artigos científicos na base de dados Scopus sobre empresa familiar durante os anos de 2011 a 2017, focando-se no tema Governança Corporativa.

Através da análise foi possível perceber que houve evolução nos estudos publicados sobre o tema, uma vez que os autores estão trabalhando mais o diálogo entre os diversos temas sobre empresa familiar, como observado a partir do ano de 2014. Além disso, foi observada uma maior valorização por estudos respaldados em estatística multivariada, está passando a ser utilizada em número maior que estatística descritiva, permitindo assim maior extração de informações que permitem enriquecer os estudos sobre seus respectivos temas.

Nota-se ainda que a revista a qual foi responsável pela exposição da maioria dos artigos do Scopus, foi o Journal of Family Business Strategy (está hospedando 44 artigos), seguida pelo Family Business Review (com 26). Outras revistas tiveram quantidades que flutuaram de 3 a 6 artigos, a título de exemplo, o Asian Social Science (com 6) e o Journal of Small Business Management (com 5). Percebe-se um número significativo que a publicação desses artigos ocorre em revistas voltadas ao continente asiático, explicado pelo fato de muitos deles se focarem no estudo de empresas familiares específicas no Japão e em Taiwan (este majoritariamente).

Considerando os trabalhos publicados sobre governança corporativa, conclui-se que apesar de ter em média 3 publicações por ano sobre o tema em relação a outros, especialmente comparando com sucessão e crescimento, muitos dos artigos que foram produzidos sobre o 


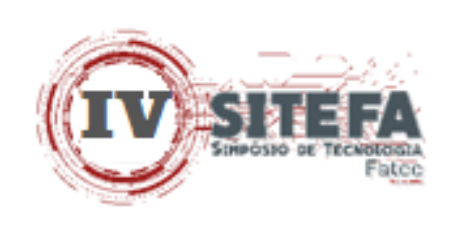

referido tema, preocuparam-se em associá-lo com outros temas, como por exemplo, sucessão e/ou então, performance e crescimento, mostrando visão e estudos mais amplos e abrangentes sobre o tema, expondo o quanto é necessário conectá-lo com outros assuntos, por ser uma discussão de extrema complexidade.

Foi possível identificar a ausência de estudos qualitativos que aliem teoria e prática, já que foi verificado que a maioria dos estudos se prendem a apenas um estudo teórico feito por outros autores, não permitindo desta forma, que novas informações sejam produzidas, atrapalhando no desenvolvimento dos trabalhos sobre empresa familiar. Além disso, os trabalhos sobre empresa familiar mostram-se ainda em fase de evolução, muitos abordando os mesmos tipos de metodologia, tais como questionário fechado e análise teórica, deixando de lado outras formas de metodologias interessantes e necessárias para se compreender mais a fundo as empresas administradas por famílias, como Focus Group e Grounded Theory.

Como limitações deste estudo bibliométrico, baseou-se apenas em um estudo de cunho unicamente teórico de uma base de dados, além da verificação apenas de artigos publicados em três línguas diferentes. Outro ponto foi que alguns dos artigos retornados pelo Scopus não puderam ser acessados e consequentemente analisados, diminuindo significativamente a amostra analisada.

Para estudos futuros, recomenda-se foco em estudos sobre Governança Corporativa, pois vem mostrando, principalmente nos anos mais recentes, números muito pouco significativos.

\section{REFERÊNCIAS}

BARRÉDY, C. In search of future alternatives for family business: Family law contributions through Civil and Common Law comparison. Futures, v. 75, 2016. Disponível em:

http://www.sciencedirect.com/science/article/pii/S0016328715300446. Acesso em: 30 maio 2017.

BETHLEM, A. S. A empresa familiar: oportunidades para pesquisa. RAUSP Management Journal, v. 29, n. 4, p. 88-97, 1994. Disponíviel em:

http://www.spell.org.br/documentos/ver/18572/a-empresa-familiar--oportunidades-parapesquisa/i/pt-br. Acesso em: 26 maio 2017.

BM\&FBOVESPA. Diretrizes da Governança Corporativa. 2014. Disponível em: http://ri.bmfbovespa.com.br/fck_temp/26_2/Diretrizes_de_Governanca_Corporativa_da_BMFBO VESPA.pdf. Acesso em: 25 maio 2017.

BRENES, E.R; MADRIGAL, K.; REQUENA, B. Corporate governance and family business performance. Journal of Business Research, v. 64, Issue 3, 2011, Pages 280-285. Disponível em: http://www.sciencedirect.com/science/article/pii/S0148296309003014. Acesso em: 24 maio 2017.

CARDOSO, Ricardo Lopes et al. Pesquisa científica em contabilidade entre 1990 e 2003. Revista de Administração de Empresas [on-line]. 2005, v. 45, n. 2, pp. 34-45. Disponível em: https://doi.org/10.1590/S0034-75902005000200004 Acesso em: 03 set. 2021. ISSN 2178-938X. https://doi.org/10.1590/S0034-75902005000200004.

DEKKER, J.; LYBAERT, N.; STEIJVERS, T.; DEPAIRE, B. The Effect of Family Business Professionalization as a Multidimensional Construct on Firm Performance. Journal of Small 


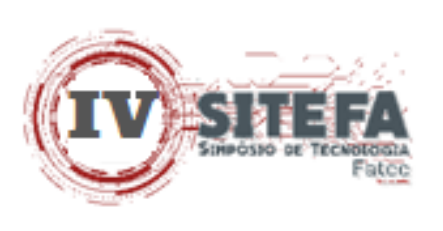

Business Management, 53: 516-538, 2015. Disponível em:

http://onlinelibrary.wiley.com/doi/10.1111/jsbm.12082/abstract. Acesso em: 25 maio 2017.

LITZ, R.A. (1995) The Family Business: Toward Definitional Clarity. Family Business Review, $8,71-81$.

MALONI, M.J.; HIATT, M.S.; ASTRACHAN, J.H. Supply management and family business: A review and call for research. Journal of Purchasing and Supply Management, v. 23, Issue 2, 2017, Pages 123-136, Disponível em:

http://www.sciencedirect.com/science/article/pii/S1478409216300875. Acesso em: 30 maio 2017.

MOREIRA, J.M.; ALTAF, J.G.; TROCCOLI, I.R. O caso RSM Pneus: estratégias de sucessão em uma empresa familiar. Revista Foco (interdisciplinary studies), v. 9, n. 1 (2016).

PADILLA-MELÉNDEZ, Antonio; DIÉGUEZ-SOTO, Julio; GARRIDO-MORENO, Aurora. (2015). Empirical research on Innovation in Family Business: literature review and proposal of an integrative framework. Revista Brasileira de Gestao de Negocios. 17. 1064-1089. 10.7819/rbgn. v17i56.1915.

MILLER, D.; MILLER, I.L.B; LESTER, R.H. Family Firm Governance, Strategic Conformity, and Performance: Institutional vs. Strategic Perspectives. Organization Science 2012 24:1, 189 209.

OLIVEIRA, J. L.; ALBUQUERQUE, A. L.; PEREIRA, R. D. Governança, Sucessão e Profissionalização em uma Empresa Familiar: (re)arranjando o lugar da família multigeracional. Revista Brasileira de Gestão de Negócios, v. 14, n. 43, p. 176-192, 2012.

REYNA, J.M.S.M; ENCALADA, J.A.D. The relationship among family business, corporate governance and firm performance: Evidence from the Mexican stock exchange. Journal of Family Business Strategy, v. 3, Issue 2,2012, Pages 106-117, Disponível em: http://www.sciencedirect.com/science/article/pii/S1877858512000216. Acesso em: 25 maio 2017.

Sucesión y su relación con endeudamiento y desempeno en empresas familiars.

Contaduría y Administración, v. 61, Issue 1, 2016, Pages 41-57, Disponível em: https://www.sciencedirect.com/science/article/pii/S0186104215000790. Acesso em: 27 maio 2017.

SANTOS, R.N.M.; SANTOS, J.L.S.; MALDONADO, M.U. Estudo bibliométrico aplicados a artigos científicos do ISI sobre inovação no âmbito do conhecimento organizacional. 2010. Disponível em: http://repositorios.questoesemrede.uff.br/repositorios/handle/123456789/1919. Acesso em: 22 maio 2017.

VELASCO, C.A.B.; PARRA, V.F.G.; GARCÍA, C.Q. Evolución de la literatura sobre empresa familiar como disciplina científica, Cuadernos de Economía y Dirección de la Empresa, v. 14, Issue 2, 2011, p. 78-90. 